Article

\title{
Innovative Development of Programmable Phase Change Materials and Their Exemplary Application
}

\author{
Kristin Lengsfeld ${ }^{1, *}$, Moritz Walter ${ }^{2}$, Martin Krus ${ }^{1}$, Sandra Pappert ${ }^{2}$ and Christian Teicht ${ }^{2} \mathbb{D}$ \\ 1 Department Hygrothermics, Fraunhofer Institute for Building Physics IBP, Fraunhoferstr. 10, \\ 83626 Valley, Germany; martin.krus@ibp.fraunhofer.de \\ 2 Department Energetic Systems, Fraunhofer Institute for Chemical Technology ICT, Joseph-von-Fraunhofer-Str. \\ 7, 76327 Pfinztal, Germany; moritz.walter@ict.fraunhofer.de (M.W.); sandra.pappert@ict.fraunhofer.de (S.P.); \\ christian.teicht@ict.fraunhofer.de (C.T.) \\ * Correspondence: kristin.lengsfeld@ibp.fraunhofer.de
}

Citation: Lengsfeld, K.; Walter, M.; Krus, M.; Pappert, S.; Teicht, C. Innovative Development of Programmable Phase Change Materials and Their Exemplary Application. Energies 2021, 14, 3440. https://doi.org/10.3390/en14123440

Academic Editor: Francesco Nocera

Received: 12 May 2021

Accepted: 8 June 2021

Published: 10 June 2021

Publisher's Note: MDPI stays neutral with regard to jurisdictional claims in published maps and institutional affiliations.

Copyright: (c) 2021 by the authors. Licensee MDPI, Basel, Switzerland. This article is an open access article distributed under the terms and conditions of the Creative Commons Attribution (CC BY) license (https:// creativecommons.org/licenses/by/ $4.0 /)$.

\begin{abstract}
The research project Fraunhofer Cluster of Excellence "Programmable Materials" aims to develop new materials that can change their properties according to defined boundaries. This article describes the development and use of a novel programmable phase change material (PCM) for latent heat storage applications. At the moment, these PCMs have a programmable trigger mechanism incorporated that activates the crystallization of the material as a reaction to a defined stimulus so that the stored heat is released. In future development stages, programmability is to be integrated on the material level. The latent heat storage that is based on PCMs can be recharged by using the energy of the sun. As an example, for a possible application of such a material, the use of a novel programmable PCM in greenhouses to support heating energy reduction or to reduce the risk of frost is explained. Using the hygrothermal simulation tool WUFI ${ }^{\circledR}$ Plus, the effects in greenhouse constructions without and with commercially available or novel programmable PCMs are calculated and presented in the present article. The calculations are based on the material data of calcium chloride hexahydrate $\left(\mathrm{CaCl}_{2}-6 \mathrm{H}_{2} \mathrm{O}\right)$, as this material serves as a basic material for the development of programmable PCM compositions. The results of the simulations show a positive impact on the indoor temperatures in greenhouses in view of the risk of frost and the reduction of heating energy. Thus, the vegetation period can be extended in combination with a lower energy load. By an eligible actuation mechanism, an inherent material system for temperature control can be created.
\end{abstract}

Keywords: PCM; programmable and switchable material; hygrothermal building simulation WUFI ${ }^{\circledR}$; thermal management; latent heat storage; energy efficiency

\section{Introduction}

Within the framework of the research project Fraunhofer Cluster of Excellence "Programmable Materials" (CPMs), novel materials and material systems are being developed, which, due to their structure, can be used to specifically and reversibly change properties in building components or to realize adaptable systems without auxiliary equipment. This opens up new areas of use and applications. One part of the cluster project deals with the development of cycle-stable programmable phase change materials (PCMs) for latent heat storage, which, due to their composition, are activated by means of a defined programmable trigger impulse. This impulse might be induced as a reaction to, e.g., an external temperature change, irradiation, or an electric or magnetic field. In consequence of the activation, the PCM releases the stored latent heat by exothermic crystallization. This activation-based utilization of PCMs opens a wider range of possible use cases compared to the classic application, e.g., as passive thermal mass in buildings [1,2].

The first development step deals with the cycle-stable basic material, the so-called switchable PCM. This kind of PCM is characterized by the ability to store its latent phase change enthalpy over a large number of cycles even below its crystallization temperature 
in a supercooled state. A switchable PCM has already been implemented in different applications. The material is used in hand-warming pouches [3] or even in larger heat storage modules for domestic heat supply, as described in [4-6]. The material is then combined with a mechanical switch that is triggered manually or by a sensor-based electronic control. Within the CPM project, a trigger mechanism made of programmable material is developed that is able to maintain the triggering activity without auxiliary energy and sensors. The aim of actual development efforts is to combine switchable PCMs with a suitable programmable switch to create a programmable PCM system in the state of a laboratory-confirmed system. The long-term goal within the cluster project is to incorporate the programmable ability to trigger itself on the material level of the PCM and implement it in a free-field test setting.

The amount of heat released from the storage material or the heat storage, respectively, is not influenced by the small trigger mechanism incorporated in the storage volume. In consequence, comparing a programmable PCM system to conventional PCMs might serve as a valid benchmark for future programmable PCMs as well. The fact that these newly developed materials and systems open up new application possibilities will be demonstrated in this work. More precisely, the impact in terms of usability and energy saving will be compared by the results of simulations. The application will be calculated and evaluated exemplarily for different variants using the hygrothermal building simulation software WUFI ${ }^{\circledR}$ Plus(Version 3.2.1.0 with an in-house add-on module for PCM, Valley, Bavaria, Germany).

Based on the simulation results, the effect of programmable PCMs in comparison to commercially available PCMs is intended to be evaluated by the exemplary application as thermal storage in greenhouse constructions. In this use case, the PCM serves as a heat buffer to protect plants and their root systems, e.g., from frost damage, as described in [7-9]. Therefore, the PCM is activated as soon as a critical temperature in the greenhouse is reached. Solar energy might be used to recharge the heat storage system in a natural way. This process can be repeated an infinite number of times, and the programmable PCM system can thus be used as an additional support to the heating of the greenhouse.

In the following, the principles of the newly developed programmable PCM are explained. Afterwards some background information about the chosen example of greenhouses for the simulations is listed, and proximate information about the input into the simulation tool WUFI ${ }^{\circledR}$ Plus and results of the application of the newly developed programmable PCM are compared to other state-of-the-art systems.

\section{Materials and Methods}

\subsection{Switchable Phase Change Materials and Programmable Phase Change Materials}

Phase change materials have a high melting enthalpy $\Delta \mathrm{H}_{\mathrm{m}}$, i.e., a lot of energy is required to transform the materials from the solid to the liquid state. During this process, the temperature in the material ideally remains constant. This material property thus enables a large amount of (latent) heat to be stored in connection with a small temperature change around the melting temperature $\mathrm{T}_{\mathrm{m}}$. Conversely, the same applies to the extraction of energy (heat of solidification) from the material. In contrast, energy absorption and release in the case of sensitive heat storage in water or bulk storage systems are achieved by changing the temperature of the storage material over a large range. The correlation between the amount of supplied and dissipated heat and temperature is shown in Figure 1 for the latent heat storage. Salt hydrates can be classified as inorganic phase change materials. A characteristic feature of this class of substances is the occurring crystallization delay, in this context also called "supercooling." Instead of crystallizing, the material changes into the metastable state of a supersaturated melt during cooling without a phase change. Crystallization only starts with a delay at the crystallization temperature $T_{\mathcal{C}}<T_{m}$. This supercooling is represented symbolically in Figure 1 as $\Delta \mathrm{T}_{\text {sup }}$. 


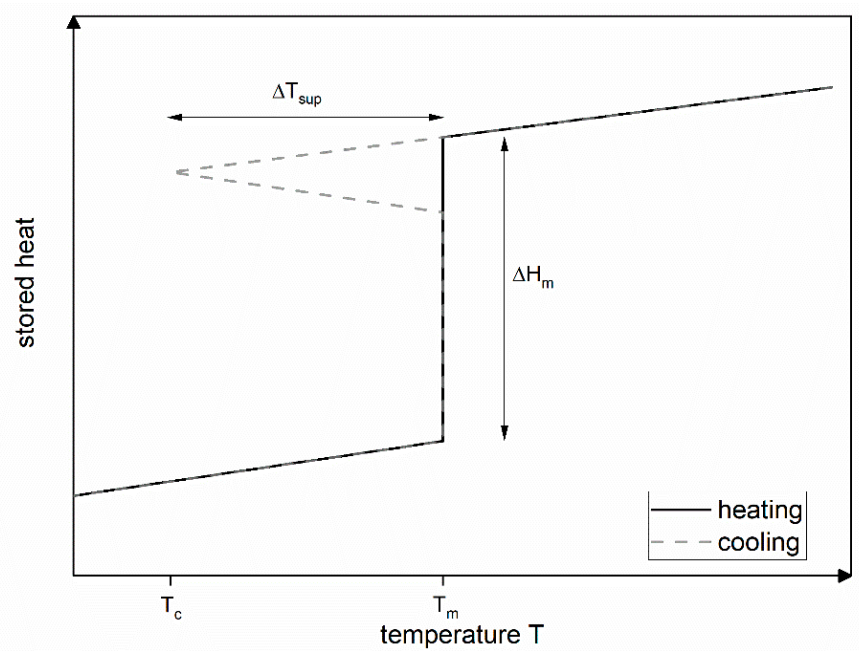

Figure 1. Exemplary depiction of the supplied heat above the material temperature with a representation of the melting enthalpy $\Delta \mathrm{H}_{\mathrm{m}}$ and supercooling during the cooling process $\Delta \mathrm{T}_{\text {sup }}$.

According to the classical crystallization theory [10], the cause for the crystallization delay is to be found in the process of formation and growth of the seed crystals and more precisely in the contribution of the surface energy required for the formation of seed crystals to the total crystallization enthalpy $\Delta \mathrm{G}_{\mathrm{c}}$. This enthalpy has a maximum $\Delta \mathrm{G}_{\text {crit }}$, which must be overcome for crystal growth. $\Delta \mathrm{G}_{\mathrm{c}}$ results from the lower dependency of the required surface energy $\Delta \mathrm{G}_{\mathrm{S}}\left(\sim \mathrm{r}^{2}\right)$ compared to the volume energy released by crystal growth $\Delta \mathrm{G}_{\mathrm{V}}$ $\left(\sim \mathrm{r}^{3}\right) . \Delta \mathrm{G}_{\mathrm{V}}$ is also dependent on the temperature of the melt $\mathrm{T}$ and the degree of the supercooling $\Delta \mathrm{T}_{\text {sup. }}$. The corresponding courses of the free enthalpies of crystal growth in relation to a crystallization nucleus are shown schematically in Figure 2. The extent and stability of the supercooling mainly depend on the material or on the material-specific critical crystallization enthalpy $\Delta \mathrm{G}_{\mathrm{c}}$. This in turn can be influenced, among other things, by the (local) manipulation of the parameters $r$ and $\Delta \mathrm{T}_{\text {sup }}$.

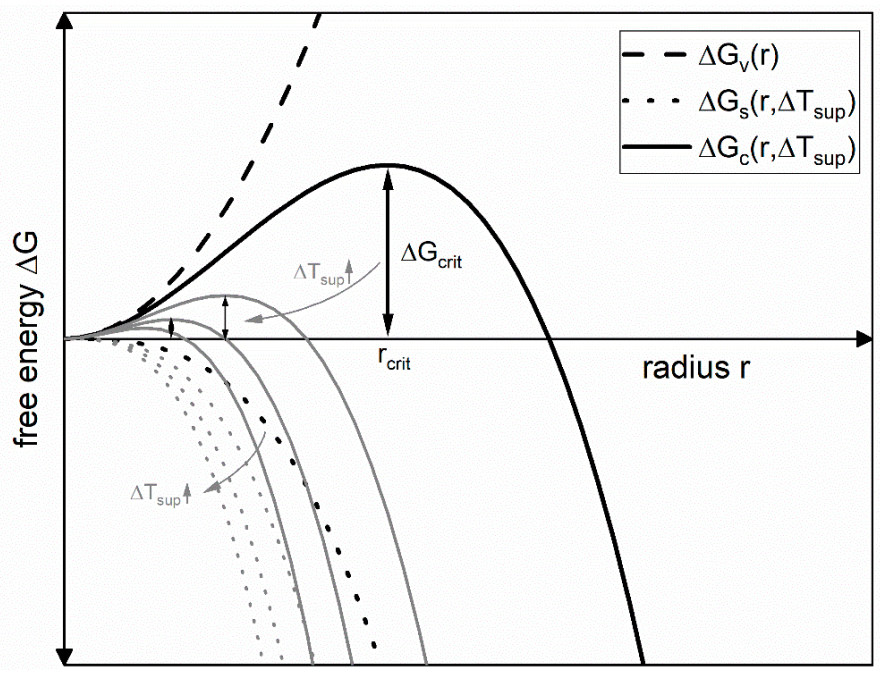

Figure 2. Representation of the critical enthalpy difference $\Delta \mathrm{G}_{\mathrm{c}}$ with maximum $\Delta \mathrm{G}_{\mathrm{crit}}$ and its dependence on the amount of supercooling $\Delta \mathrm{T}_{\text {sup }}$, as well as on the radius $\mathrm{r}$ of the idealized crystallization nuclei [10].

A switchable phase change material is defined as a phase change material that releases the phase transformation energy stored in its supercooled melt only in interaction with a controllable trigger. Therefore, some necessary requirements have to be satisfied by the PCM. Besides an extensive and reliable inclination for supercooling of at least $20 \mathrm{~K}$, 
the material has to be cycle stable, which means that there is no noteworthy loss in phase change enthalpy over a large number of cycles.

A programmable phase change material is defined as a PCM that is modified to respond to a chosen external stimulus in the way that it releases the stored phase change enthalpy by exothermic crystallization and without an additional macroscopic switching mechanism. As mentioned before, current programmable PCM systems consist of a switchable PCM where a programmable triggering mechanism is incorporated. The programmable trigger mechanism is the second main emphasis of research efforts. It consists of a physical trigger and a programmable switching mechanism. The programmable switching mechanism might respond to various types of external stimuli as, e.g., magnetic or electric fields, temperature, irradiation, pressure, or humidity. One functional design is described in the following section, and Figure 3 shows an exemplary sketch of the programmable PCM-gel actuator.

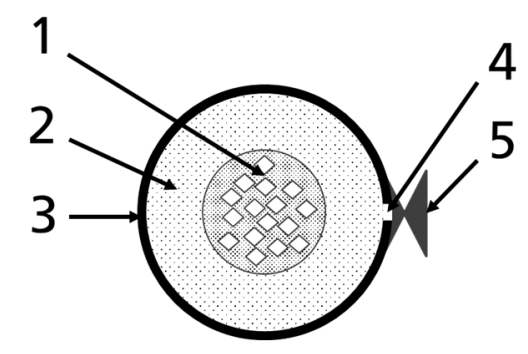

Figure 3. Exemplary sketch of the switching mechanism with nucleating agent dispersed in a small portion of the PCM (1), immobilized PCM layer (2), encapsulation layer (3) with a small opening (4), and sealing mechanism (5).

Classical crystallization theory indicates that a suitable crystallization surface might be used as a physical trigger for activating the exothermic crystallization of the PCM. This surface might be exposed by a seed crystal of the PCM itself or by a suitable nucleating agent. Both approaches have been verified in numerous in-house experiments. With regard to nucleating agents, it has been observed that homogeneous dispersion of the nucleating agent is crucial for a reliable initiation of the crystallization. Local fixation of nucleating agents, e.g., on the PCM encapsulation wall, had no reproducible effect on the crystallization. The actual switching mechanism, therefore, uses both nucleating agents and the crystalized PCM itself. A nucleating agent is dispersed in a small portion of the PCM (1). Within this small portion of "seeding PCM," the range of supercooling is eliminated or at least reduced to a minimum. To prevent the migration of nucleating agents and resulting contamination of the whole PCM, this small portion is surrounded by an immobilized PCM layer (2) and an encapsulation layer (3) with a single small opening (4). This opening is sealed by the switching mechanism (5). To maintain the programmable character of this switching mechanism, it can be realized of various responsive materials, as, e.g., shape memory polymer, which is also investigated by a section of the CPM project.

\subsection{Application of Programmable Phase Change Materials-Greenhouse Constructions}

In agriculture, vegetable and ornamental plants are bred worldwide and cultivated in greenhouses. Various statistical analyses in $[11,12]$ show that the cultivation areas in greenhouses are increasing every year, especially in vegetable cultivation. The two graphs in Figure 4 show the development of cultivated areas of greenhouse crops in Germany and the Netherlands for several years. Both graphs show that there is a continuous increase. In the flower and ornamental plant cultivation sector, about $25 \%$ of the area is cultivated under glass, which, according to [13], corresponds to an area of about 1629 hectares.

Greenhouses are often single glazed and are, therefore, highly energy intensive to be operated. However, they also offer optimum conditions, as they provide the highest light transmission. Despite the possibility of saving energy, double or triple glazing is not yet widely used in this area because of the associated costs and reduced light transmission, 
which is crucial for plant growth. Yet, it is also possible that, especially at low outside temperatures, the light transmission of thermal insulating glazing may be higher at times, as there is no condensation on the inside. The development of low-energy greenhouses has already been investigated by [14]. In this context, different approaches to energy saving were analyzed from both an energy and lighting point of view.

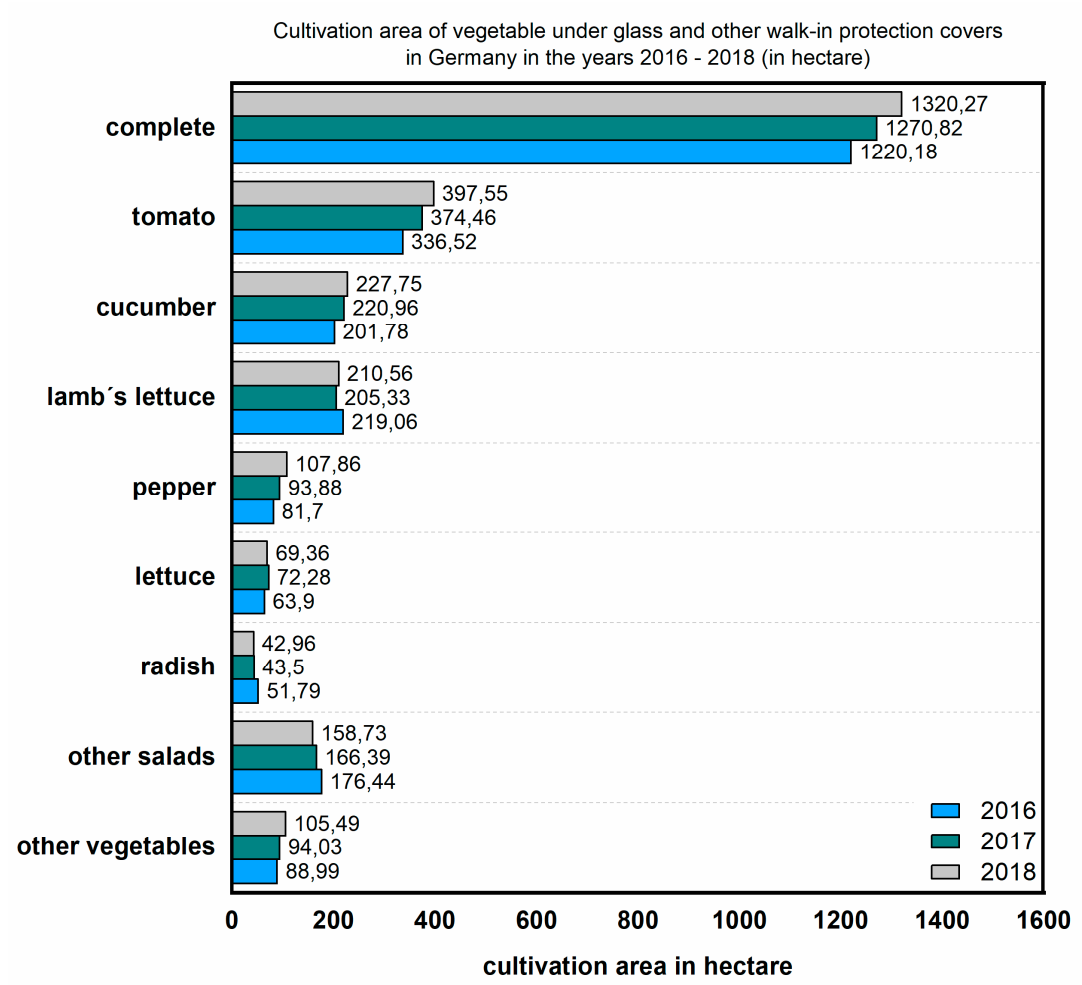

(a)

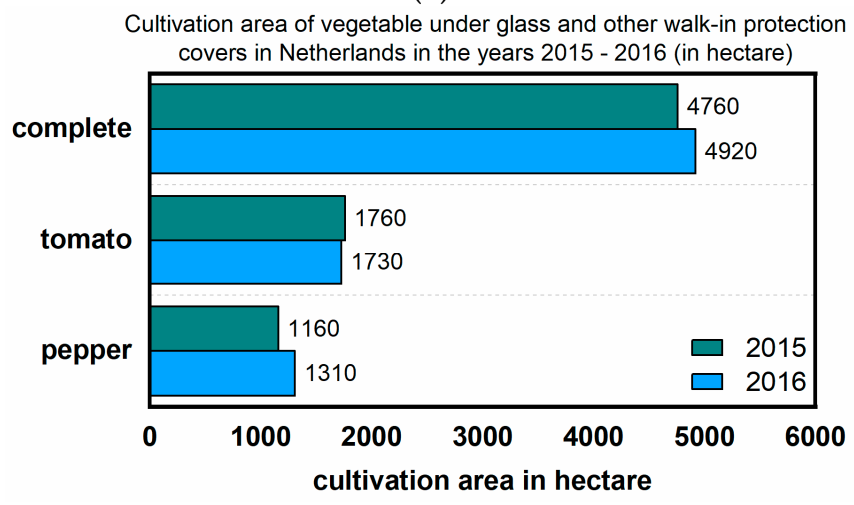

(b)

Figure 4. Statistical analyses of the greenhouse cultivation areas: (a) development of vegetable cultivation under glass in Germany in the years 2016-2018 Reproduced from [11], Publisher: Statistisches Bundesamt; (b) development of vegetable cultivation under glass in the Netherlands in 2015-2016 Reproduced from [12], Publisher: Statista Research Department.

The energy required to operate greenhouses generally depends on the plant cultures and the outdoor climate conditions. The use of greenhouses has the advantage that the vegetation phase/development of the plants can be optimized on the one hand, and, on the other hand, the period for the cultivation of the plants can be extended compared to open-field cultivation. According to the type of plant, it is important to have very uniform temperatures in greenhouses, as plants such as gerberas, for example, are very sensitive to temperature fluctuations and require a certain temperature within a narrow 
range throughout the year [15]. Depending on the plant species, the greenhouse must be heated at night even during the summer months to allow the plants to grow. It may also be necessary to heat the greenhouse during the transitional periods of spring and fall to prevent frost damage or a drop in temperatures to critical levels for the plants.

The use of phase change materials (PCMs) is intended to create a way of reducing temperature fluctuations and avoiding the risk of frost damage to plants in the greenhouse. By releasing the energy stored in the PCM, the required heating output could be reduced during the transitional months, and the utilization phase of the greenhouses could be extended. The application of a conventional PCM in greenhouses is summarized, e.g., in [7-9]. One of the advantages of programmable PCMs over a conventional PCM is that the time of activation of the exothermic process can be explicitly controlled according to the requirements. By using the solar energy entering the greenhouse through the glazing, the PCM storages can be recharged naturally and without additional energy input after activation to be ready for use again at the next critical temperature range.

Based on this knowledge, the use of commercially available and programmable PCMs is further investigated by means of simulation calculations for a greenhouse. The temperature range in which the PCM storage units are supposed to work strongly depends on the use and requirements of the plant cultivations in the greenhouse. In the following, a distinction is made between two applications: the first application is to prevent frost damage caused by temperatures below freezing point, and the second application is to ensure that the temperature in the greenhouse does not drop below $12{ }^{\circ} \mathrm{C}$ to protect sensitive plant cultures.

\subsection{Programmable Phase Change Materials for Greenhouse Applications}

The usable heat of heat storage based on programmable PCMs depends on the selection of the PCM, the amount of PCM, and the prevailing supercooling of the melt. These parameters also represent necessary input values for the hygrothermal building simulation.

At the moment, a suitable programmable PCM system is not available for greenhouse application. A corresponding material might be synthesized as eutectic mixtures of calcium chloride hexahydrate $\left(\mathrm{CaCl}_{2}-6 \mathrm{H}_{2} \mathrm{O}\right)$ and other additives [16]. The suitability, e.g., the stable supercooling range of such materials, is the subject of current in-house investigations.

For this reason, and as the goal of this simulation study is the determination of the general potential of a programmable PCM in greenhouse applications, the simulation is firstly carried out on the basis of the material data of calcium chloride hexahydrate. The results can then be evaluated as a qualitative assessment of the potential of implementing programmable phase change materials in greenhouse operation.

As a raw material, $\mathrm{CaCl}_{2}-6 \mathrm{H}_{2} \mathrm{O}$ is a very promising candidate for programmable PCM systems, which binds 6 molecules of water per salt molecule in its crystal structure. At a temperature of $29-30{ }^{\circ} \mathrm{C}$, the salt hydrate melts, and the salt dissolves in its crystal water. The mass-related enthalpy of fusion is about $190 \mathrm{~J} / \mathrm{g}$ [17] (confirmed by our measurements). As a result of our measurements, the material reliably remains in a supercooled state down to a temperature of $7{ }^{\circ} \mathrm{C}$ without crystallizing. The stable supercooling interval thus amounts to approximately $22{ }^{\circ} \mathrm{C}$.

The material data for the programmable PCM in the hygrothermal simulation are summarized in Table 1.

\subsection{Procedure of Hygrothermal Building Simulations}

Based on the information specified above and the investigation report [18], a 3D simulation model of a Venlo greenhouse is developed for the hygrothermal building simulations. For the investigations, the hygrothermal building simulation tool WUFI ${ }^{\circledR}$ Plus is used. Its capabilities and verifications are described in $[19,20]$. The simulations performed are intended to show how the use of commercially available PCMs and optimized, programmable phase change materials can minimize the risk of frost in the transition period 
on the one hand, and, on the other, reduce the heating energy demand. The calculated results are then graphically evaluated and assessed.

Table 1. Essential input of estimated material data of programmable PCM for hygrothermal simulation.

melting Temperature (range)
enthalpy of fusion
minimum supercooling temperature
effective crystallization temperature (set by trigger mechanism)

$18^{\circ} \mathrm{C}-20^{\circ} \mathrm{C}$
$190 \mathrm{~J} \mathrm{~g} \mathrm{~g}^{-1}$
$7^{\circ} \mathrm{C}$
$15^{\circ} \mathrm{C}$

The calculations are carried out according to the flow chart shown in Figure 5. In addition to the materials used for the individual building components, the calculations also consider boundary conditions such as air change, moisture production, the capacity of the heating system, and, if necessary, other technical equipment for the air conditioning in the examined room, as well as the quantity and switching point of the PCM used. This requires suitable hygrothermal material characteristics for the used building materials and the applied phase change material. As a result, information about the situation at the enclosure surfaces, the indoor air, and the energy demand at real transient boundary conditions is obtained.

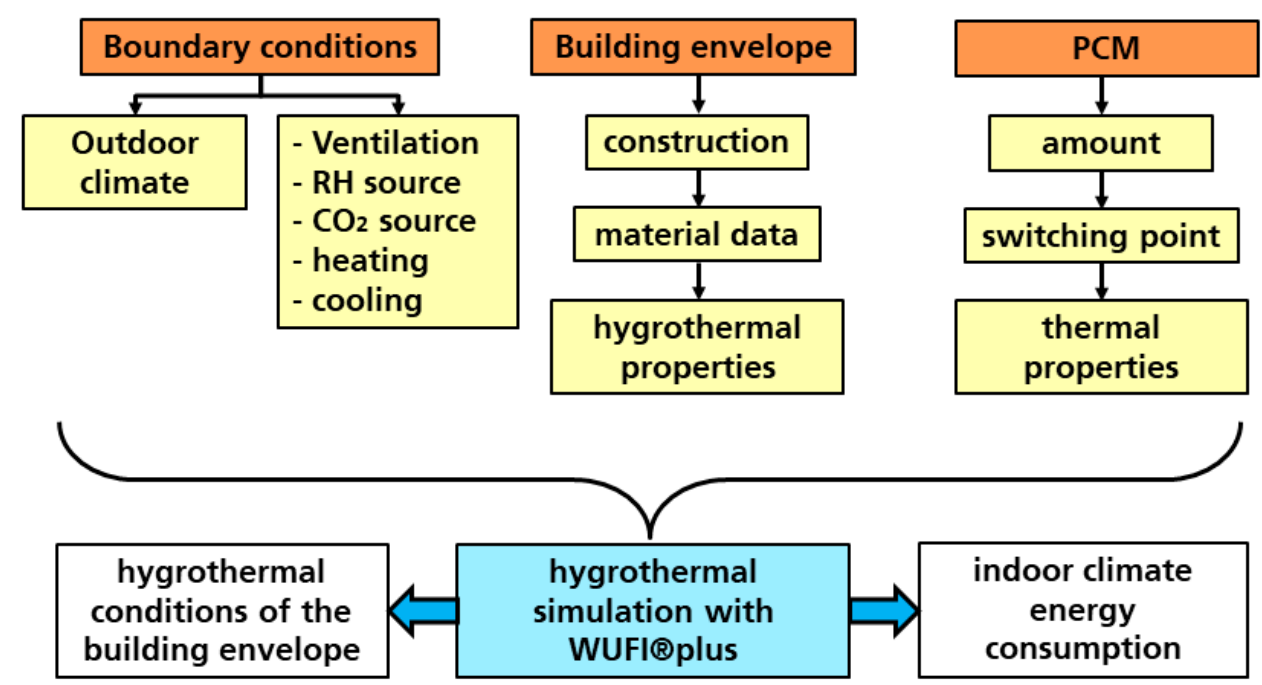

Figure 5. Flowchart for carrying out a hygrothermal building simulation using PCMs.

As a basis for the calculations, a three-aisled glasshouse in Venlo construction is implemented (see Figure 6). The greenhouse has a floor area of $144 \mathrm{~m}^{2}$ and a net volume of approximately $650 \mathrm{~m}^{3}$. It is assumed that $80 \%$ of the area is equipped with planting tables in which the PCM can be integrated. A sun protection system is not considered in the simulations at this stage, but its implementation is planned for further calculations. The Friedrichshafen region is used for the outdoor climate, as the region around Lake Constance is one of the main fruit and vegetable growing areas in Germany.

In addition to the scenarios with different PCMs, it is being investigated what advantage can be expected of using thermal insulation glazing (WSG) (U-value $=1.1 \mathrm{~W} \mathrm{~m}^{-2} \mathrm{~K}^{-1}$ ) compared to single glazing $(\mathrm{ESG})\left(\mathrm{U}\right.$-value $\left.=6 \mathrm{~W} \mathrm{~m}^{-2} \mathrm{~K}^{-1}\right)$ in terms of minimum temperature and hours with temperatures below the freezing point. A constant infiltration of $0.15 \mathrm{~h}^{-1}$ is assumed for the ventilation of the greenhouse. The mechanical ventilation is controlled in dependence on the temperature. At indoor air temperatures up to $34{ }^{\circ} \mathrm{C}$, the air exchange rate is $0.8 \mathrm{~h}^{-1}$ and increases to $10 \mathrm{~h}^{-1}$ above $34^{\circ} \mathrm{C}$ in order to prevent overheating in the greenhouse. Heating is not applied when comparing single-pane and thermal insulation glazing. Based on these standard variants, the use of a newly developed, programmable phase change material is further investigated with regard to the risk of 
frost in the greenhouse. For this purpose, a programmable PCM is implemented in the simulations, which is activated at an outdoor air temperature of $0{ }^{\circ} \mathrm{C}$.

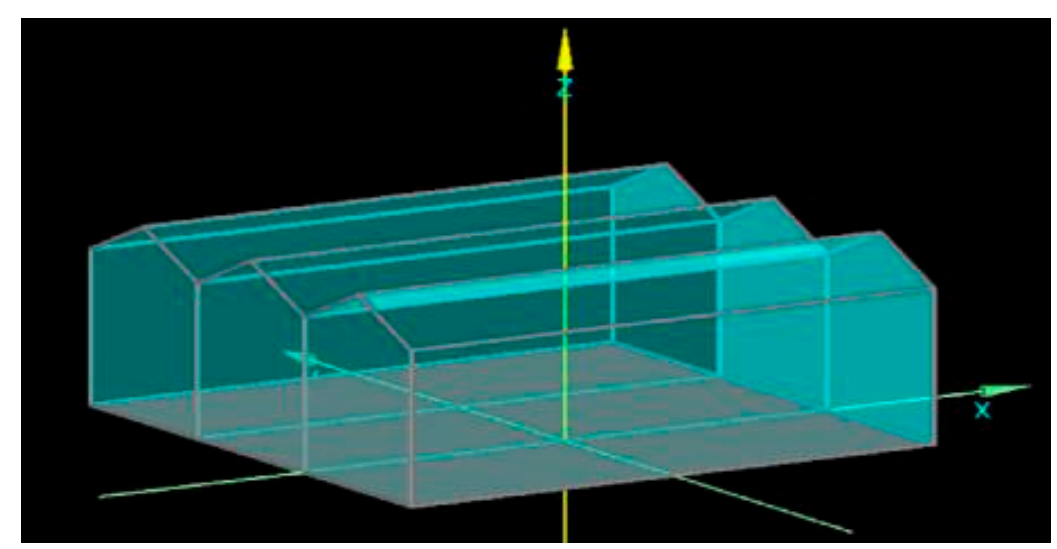

Figure 6. Venlo greenhouse designed with the simulation software.

In a further step, the effect of the newly developed, programmable latent heat material is investigated for a variant with integrated heating and a minimum temperature of $12{ }^{\circ} \mathrm{C}$. In this variant, the PCM switches in response to the outdoor air temperature at $15^{\circ} \mathrm{C}$ to release energy. The material itself has a melting range between 18 and $20^{\circ} \mathrm{C}$ and can be melted at these temperatures during warmer periods, e.g., during the day. For the calculation variant with a minimum indoor air temperature of $12{ }^{\circ} \mathrm{C}$, a commercial PCM with a melting/solidification range of 18 and $19^{\circ} \mathrm{C}$, respectively, is used for comparison. The simulations are evaluated in terms of the frequency with which the temperature in the greenhouse falls below the set lower temperature limit of $0{ }^{\circ} \mathrm{C}$, and with regard to the heating energy required to guarantee a minimum temperature of $12^{\circ} \mathrm{C}$. The results are shown in the following graphs and tables.

\section{Results}

The following evaluations regarding the effect of the applied programmable phase change material are based on the temperature curves in a greenhouse without heating. Figure 7 shows the two temperature curves over one year for a greenhouse with single glazing (red line) compared to thermal insulation glazing (blue line). Due to the glazing type, the greenhouse with single glazing cools down considerably more at night. During the day, thermal insulation glazing leads to higher temperatures and increased ventilation requirements compared to single glazing. Table 2 presents the minimum temperatures of the outdoor air and the results of the different simulation variants. The number of hours (based on one year) during which the interior temperature drops below $0{ }^{\circ} \mathrm{C}$ is summarized. For the two variants with a programmable PCM, the latent heat storage system is activated in the simulation as soon as the outdoor air temperature falls below $0{ }^{\circ} \mathrm{C}$. The released heat indicates that the risk of frost in the greenhouse can be reduced by approximately $20 \%$ in a construction with tempered glass. In a greenhouse equipped with thermal insulation glazing, this can even be reduced by approximately $85 \%$ to a few hours per year.

In vegetable and plant cultivation, there are many varieties that require higher minimum temperatures. The use of programmable PCMs for this purpose is being further investigated in a greenhouse with heating and thermal insulation glazing. For the simulation, a heating system with a $16 \mathrm{~kW}$ output is used, which is controlled such that the temperature in the greenhouse does not drop below $12{ }^{\circ} \mathrm{C}$, if possible. In the variant using the newly developed PCM, the control parameter is based on the PCM being activated at an outdoor air temperature of $15^{\circ} \mathrm{C}$ and recharged between 18 and $20^{\circ} \mathrm{C}$. In contrast, the commercially available PCM has a melting and solidification temperature of $18 / 19^{\circ} \mathrm{C}$. Figure 8 shows an example of the time curve of indoor temperatures over a period of 14 days in March. Here, the different effects of commercial and programmable latent heat 
storages become apparent. In Figure 8, the blue line shows the temperature curve of the indoor air temperature for the greenhouse variant with thermal insulation glazing and a heating control for temperatures above $12{ }^{\circ} \mathrm{C}$ and a higher air change rate of $10 \mathrm{~h}^{-1}$ over $34^{\circ} \mathrm{C}$. Depending on the influence and operation of the heating system or rather high air change rate the minimal and maximal temperature range in the greenhouse can be adhered to without PCM.

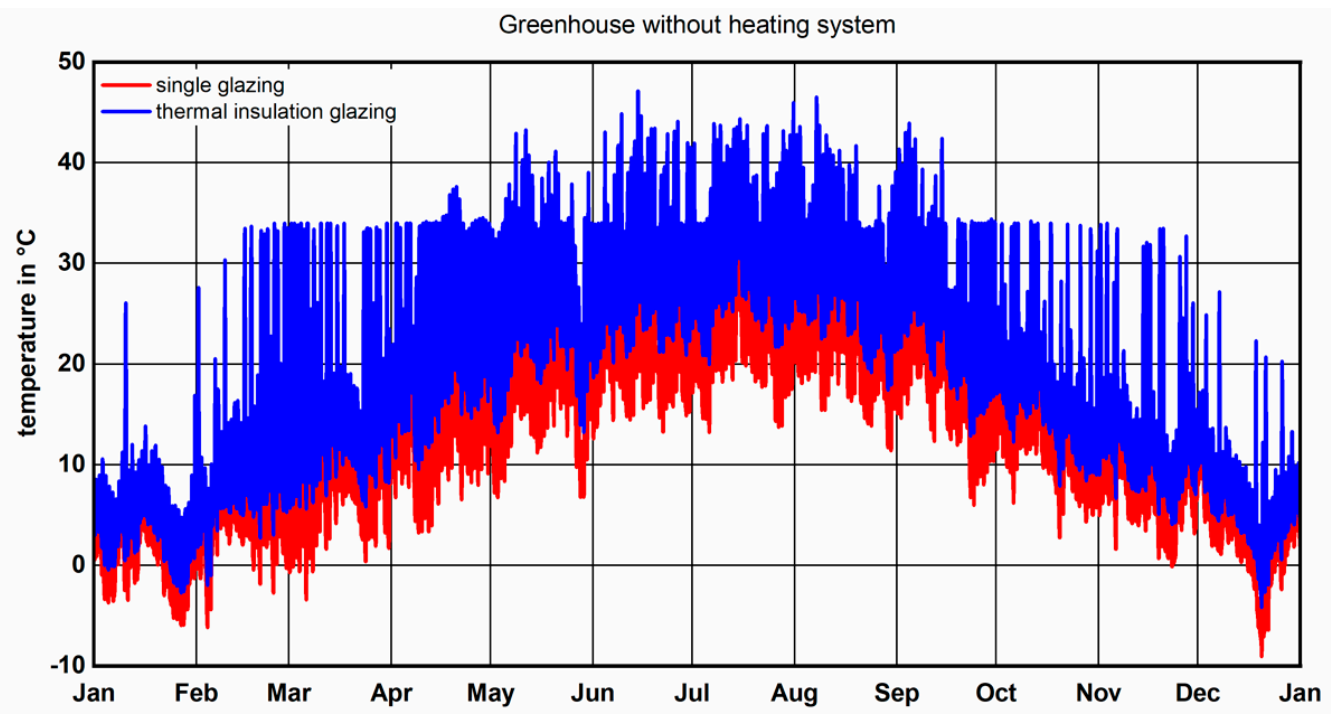

Figure 7. Comparison of the time dependence of indoor air temperatures for single (red) and thermal insulation glazing (blue).

Table 2. Minimum temperatures and number of hours below $0^{\circ} \mathrm{C}$ during the year.

\begin{tabular}{lcc}
\hline \multicolumn{1}{c}{ Variants } & Minimum Temperature $\left({ }^{\circ} \mathbf{C}\right)$ & Number of Hours $<\mathbf{0}^{\circ} \mathbf{C}\left(\mathbf{h a}^{-\mathbf{1})}\right.$ \\
\hline outdoor air & -11.8 & 1082 \\
tempered glass without PCM & -9.1 & 599 \\
tempered glass with programmable PCM & -8.9 & 482 \\
thermal insulation glazing without PCM & -4.2 & 165 \\
thermal insulation glazing with programmable PCM & -1.8 & 25 \\
\hline
\end{tabular}

When using commercially available PCMs, the stored energy is released as soon as the temperature in the latent heat storage reaches the melting point of $18^{\circ} \mathrm{C}$. The introduced latent heat is reflected in the temperature curve by a brief slowing down of the cooling in the room. Nevertheless, an additional heating system is still required in the period shown to maintain the minimum temperature of $12{ }^{\circ} \mathrm{C}$, as some of the heat is released too early, and, thus, the temperature in the greenhouse is kept at a higher level than necessary. Due to the larger temperature difference to the ambient air, larger heat losses occur, and the stored heat is not sufficient to maintain the temperature in the greenhouse above $12{ }^{\circ} \mathrm{C}$. The green line shows the effect of a programmable PCM on the curve of the interior temperature in the greenhouse. Being able to define the switching parameter for the release of the latent heat allows for a more targeted heat release. In this application, the switching point of the PCM is set to an outside temperature of $15^{\circ} \mathrm{C}$. The effect of the released energy is shown with the curve of the indoor air temperature (green line). It becomes evident that in the represented time period, the indoor air temperature is always above $12{ }^{\circ} \mathrm{C}$ due to the release of latent heat, and, therefore, no additional heating energy needs to be introduced. Furthermore, the temperature curve in Figure 8 shows that the room temperatures of the variants with PCM rise with a slight time delay, as the PCM storage has to store thermal energy for the next cycle after being activated at night. The daily maximum temperatures are thus reached less frequently compared to the standard design, implying that the increased air exchange rate above $34^{\circ} \mathrm{C}$ needs to be ensured less frequently by ventilation. The extent to which 
the heating energy requirement is influenced by the use of commercially available and programmable PCM can be seen in the comparison of the calculated consumption values in Table 3. Related to a whole year, the heating requirement can be reduced by approximately $20 \%$ when using a programmable PCM. The largest positive effect on the reduction of the heating requirement due to the additional heat energy of the latent heat storage can be identified in spring and autumn. This can be seen in the comparison of the curves of the calculated thermal energy demand values in Figure 9 for the whole year and even more detailed in Figure 10 for spring. Figure 10 shows that, starting from approximately mid-February, the use of the programmable latent heat storage leads considerably to a reduction of the required heating energy.

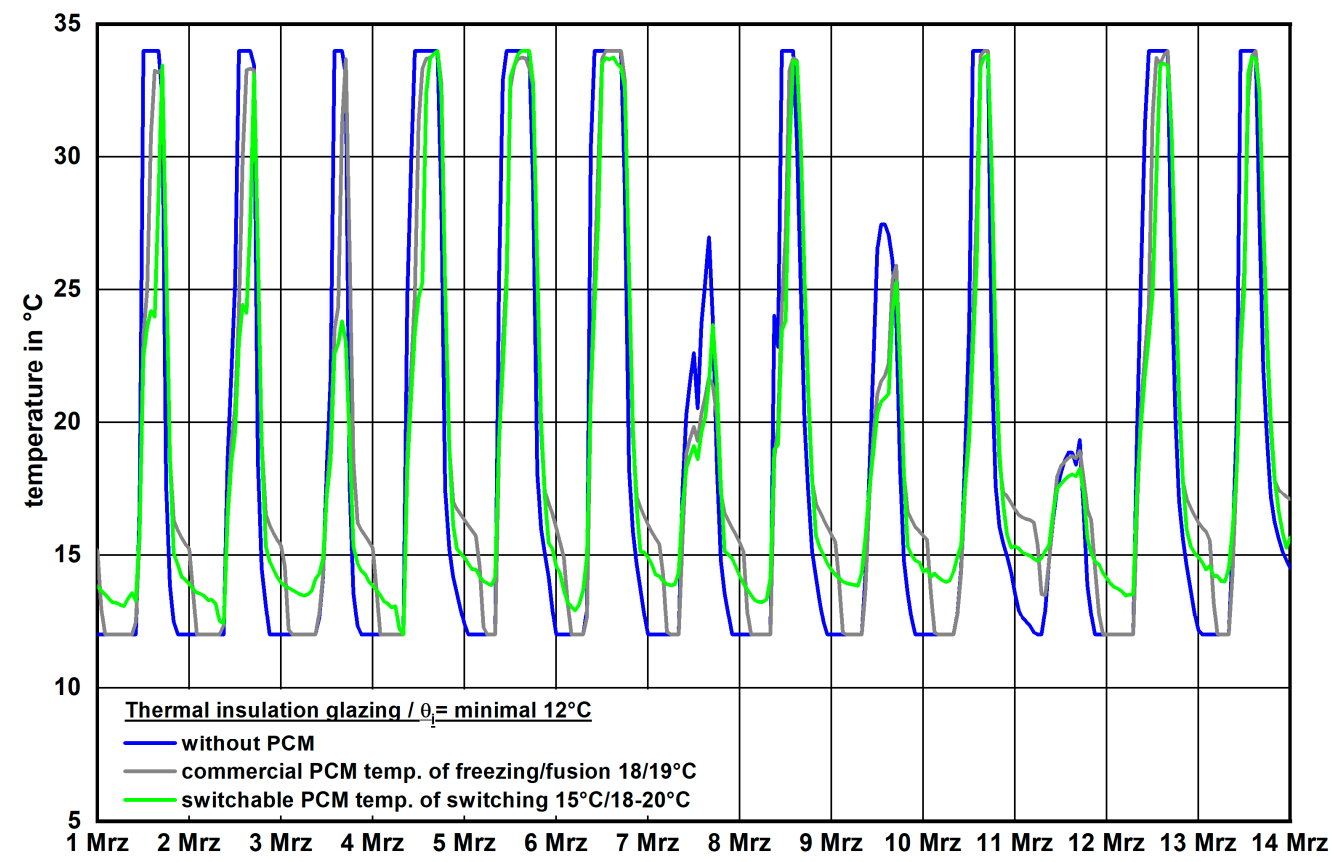

Figure 8. Comparison of the time dependence of the indoor air temperatures when using thermal insulation glazing without a PCM (blue), with a commercially available PCM (gray), and with a newly developed, programmable PCM (green), which is activated at an outdoor air temperature of $15^{\circ} \mathrm{C}$.

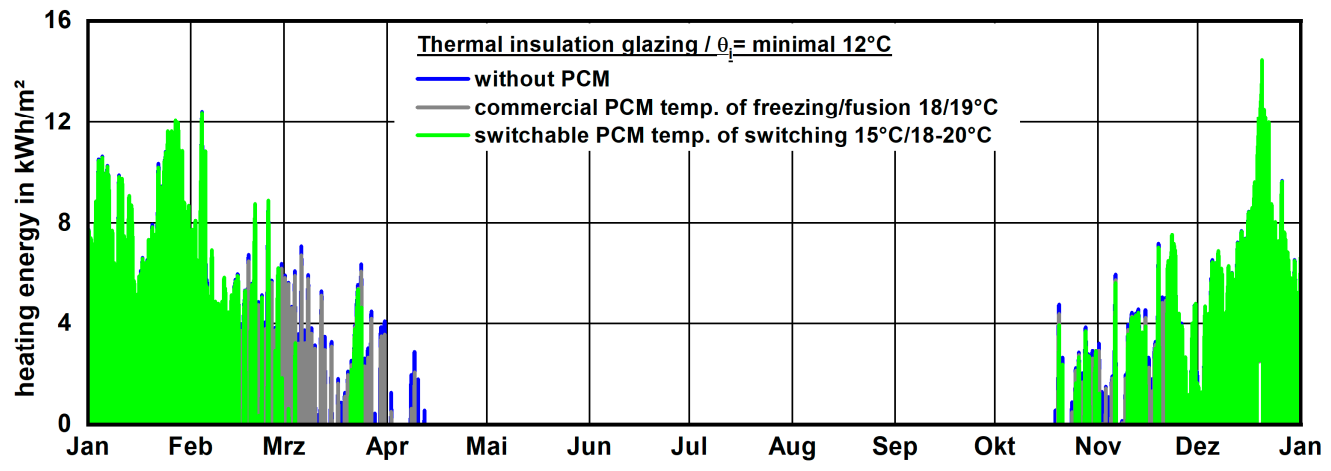

Figure 9. Comparison of the required heating energy during a year when using thermal insulation glazing without a PCM (blue), with a commercially available PCM (gray), and with a newly developed, programmable PCM (green). 
Table 3. Required heating energy to achieve a minimum temperature of $12{ }^{\circ} \mathrm{C}$ in the greenhouse.

\begin{tabular}{|c|c|c|}
\hline Variants & $\begin{array}{l}\text { Annual Heating Energy } \\
\quad\left(\mathrm{kWh} \mathrm{m}^{-2} \mathrm{a}^{-1}\right)\end{array}$ & $\begin{array}{c}\text { Heating Energy in the Period } \\
\text { 15.02-01.11. }\left(\mathrm{kWh} \mathrm{m}^{-2}\right)\end{array}$ \\
\hline without PCM & 86 & 13 \\
\hline commercially available PCM & 77 & 9 \\
\hline programmable PCM & 70 & 4 \\
\hline
\end{tabular}

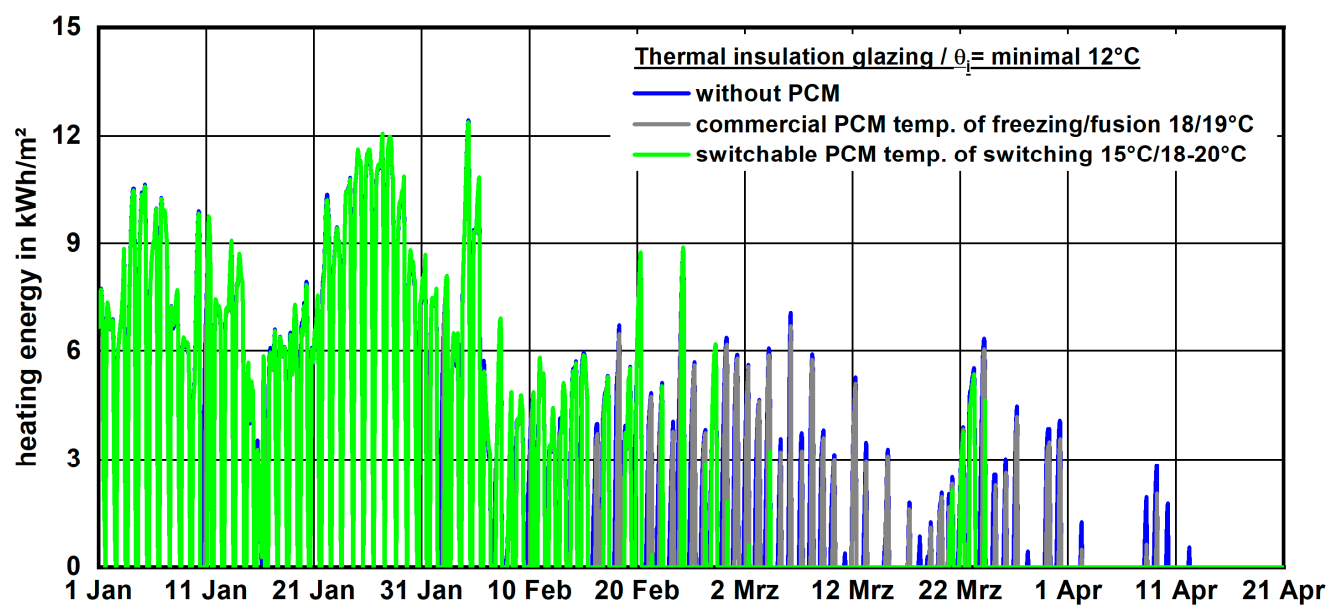

Figure 10. Comparison of the required heating energy for the period from 1 January to 21 April when using thermal insulation glazing without a PCM (blue), with a commercially available PCM (gray), and with a newly developed, programmable PCM (green).

\section{Summary}

Within the framework of the research project Fraunhofer Cluster of Excellence "Programmable Materials," programmable phase change materials are being developed, which offer new possibilities for energy saving and temperature control due to their composition and, in particular, the possibility of external (largely temperature-independent) activation of the phase change and the associated energy release. A possible application scenario was developed and presented by means of hygrothermal building simulations (WUFI ${ }^{\circledR}$ Plus), based on the example of greenhouses. By integrating a programmable PCM, which is adapted to the application scenario, on the one hand, the risk of frost in the greenhouse can be reduced by activating the heat output, and, on the other hand, a significant reduction of the heating energy required to maintain a minimum temperature can be achieved. The main advantage of these heat storage systems in the considered application is that the storage tanks are recharged naturally by solar energy. Thus, the utilization and vegetation phase can be effectively optimized and extended without any additional heat source. In comparison to greenhouses with single glazing and thermal insulation glazing without heat storage, the calculation results show that the use of phase change materials can reduce the number of hours in which frost can occur in the greenhouse by up to $85 \%$. Furthermore, the use of an optimized and programmable PCM can reduce the heating requirement by approximately $20 \%$ if the minimum temperature in the greenhouse does not drop below $12{ }^{\circ} \mathrm{C}$. Due to the variety of material design options, further savings potential can be tapped in the future. One of the next steps is to implement the newly developed programmable PCM in a free-field test setting to investigate and monitor their behavior under real conditions.

In this article, the potential of programmable phase change materials is demonstrated by the example of vegetable and ornamental plant cultivation in greenhouses. However, the development of programmable materials still contains a wide range of new and completely different applications and uses, not only for agriculture, e.g., for air-conditioning systems. In particular, there is the possibility to integrate the switching criteria and hence the control technology of the system directly into the material by means of suitable actuation 
mechanisms. Thus, a material-inherent system for temperature control can be created, which, ideally, requires no further electronic control technology.

Author Contributions: Conceptualization, K.L. and M.W.; methodology, K.L., M.K., M.W., S.P. and C.T.; software, K.L. and M.K.; investigation, K.L. and M.W.; writing-original draft preparation, K.L. and M.W.; writing—review and editing, K.L., M.K., M.W., S.P. and C.T.; visualization, K.L. and M.W.; supervision, M.K. and C.T.; project administration, M.K. and C.T. All authors have read and agreed to the published version of the manuscript.

Funding: This research was funded by Fraunhofer Cluster of Excellence "Programmable Materials".

Institutional Review Board Statement: Not applicable.

Informed Consent Statement: Not applicable.

Data Availability Statement: Not applicable.

Conflicts of Interest: The authors declare no conflict of interest.

\section{References}

1. Di Bari, R.; Horn, R.; Nienborg, B.; Klinker, F.; Kieseritzky, E.; Pawelz, F. The Environmental Potential of Phase Change Materials in Building Applications. A Multiple Case Investigation Based on Life Cycle Assessment and Building Simulation. Energies 2020, 13, 3045. [CrossRef]

2. Bland, A.; Khzouz, M.; Statheros, T.; Gkanas, E.I. PCMs for Residential Building Applications: A Short Review Focused on Disadvantages and Proposals for Future Development. Buildings 2017, 7, 78. [CrossRef]

3. Kafle, B.P.; Devkota, S.; Uprety, B.; Park, K.Y.; Basnet, N.; Shakya, A.; Tiwari, S.K. Storing Solar Energy in Sodium Acetate-Based Hand Warmers Using Light-Absorbing Particles. ACS Appl. Energy Mater. 2020, 3, 11772-11780. [CrossRef]

4. H M Heizkörper Gmbh \& Co Kg. Latentwärmespeicher Mit Einer Vorrichtung zur Auslösung der Kristallisation in Einem Phasenwechselmaterial und Verfahren zur Auslösung der Kristallisation in Einem Phasenwechselmaterial. EP15183577A, 2 September 2015.

5. Dannemand, M.; Dragsted, J.; Fan, J.; Johansen, J.B.; Kong, W.; Furbo, S. Experimental investigations on prototype heat storage units utilizing stable supercooling of sodium acetate trihydrate mixtures. Appl. Energy 2016, 169, 72-80. [CrossRef]

6. Dannemand, M.; Kong, W.; Johansen, J.B.; Furbo, S. Laboratory Test of a Cylindrical Heat Storage Module with Water and Sodium Acetate Trihydrate. Energy Procedia 2016, 91, 122-127. [CrossRef]

7. Kürklü, A. Energy storage applications in greenhouses by means of phase change materials (PCMs): A review. Renew. Energy 1998, 13, 89-103. [CrossRef]

8. Benli, H.; Durmuş, A. Performance analysis of a latent heat storage system with phase change material for new designed solar collectors in greenhouse heating. Sol. Energy 2009, 83, 2109-2119. [CrossRef]

9. Bouadila, S.; Kooli, S.; Skouri, S.; Lazaar, M.; Farhat, A. Improvement of the greenhouse climate using a solar air heater with latent storage energy. Energy 2014, 64, 663-672. [CrossRef]

10. Meyer, K. Physikalisch-Chemische Kristallographie. 2. Aufl; VEB Deutscher Verlag für Grundstoffindustrie: Leipzig, Germany, 1977.

11. Henrich, P. Anbaufläche von Gemüse unter Glas in Deutschland bis 2018. In Gemüseerhebung 2018; Statista, Statistisches Bundesamt: Wiesbaden, Germany, 2019; Seite 22.

12. Statista Research Department: Anbau von Gemüse unter Glas in den Niederlanden bis 2016. Herkunftsverweis: Fruchthandel Online, November 2016. Available online: https:/ / de.statista.com/statistik/daten/studie/640642/umfrage/anbauflaechen-vongemuese-unter-glas-niederlande/ (accessed on 29 July 2020).

13. Hohmann, M. Landwirtschaftliche Betriebe und Anbauflächen für Blumen und Zierpflanzen in Deutschland. In Bodennutzung der Betriebe - Landwirschaftlich genutzte Flächen-Fachserie 3 Reihe 3.1.2-2019; Statista, Statistisches Bundesamt: Wiesbaden, Germany, 2019; Seite 4.

14. Tantau, H.-J. Das Niedrigenergiegewächshaus-Methode zur Analyse der Wärmeströme und der PAR-Durchlässigkeit. Landtechnik 2012, 67, 196-204. [CrossRef]

15. Bartsch, L. Machbarkeitsstudie für die solarthermische Beheizungsunterstützung von Gewächshäusern im Bestand. Bachelorarbeit 2012, Hochschule für Angewandte Wissenschaften Hamburg—Fakultät Life Sciences—Studiengang Ökotrophologie. 2012. Available online: http:/ / edoc.sub.uni-hamburg.de/haw/volltexte/2013/1959/ (accessed on 15 April 2019).

16. Kimura, H.; Kai, J. Mixtures of calcium chloride hexahydrate with some salt hydrates or anhydrous salts as latent heat storage materials. Energy Convers. Manag. 1988, 28, 197-200. [CrossRef]

17. Fischer, L.J. Phasenwechselmaterialien (PCM) für Latent-Wärmespeicher. In VDI-Wärmeatlas; Stephan, P., Mewes, D., Kabelac, S., Kind, M., Schaber, K., Wetzel, T., Eds.; Springer: Berlin/Heidelberg, Germany, 2019; pp. 1-20. ISBN 978-3-662-52991-1.

18. Bettin, A. Energy consumption and plant growth in a greenhouse covered with low-e glass (in German: Prüfung der Produktionseigenschaften und des Energieverbrauchs eines Niedrigenergie-Gewächshauses auf der Basis beschichteter Gläser). August 2018. Available online: https:/ / www.researchgate.net/publication/327035341 (accessed on 15 April 2019). [CrossRef] 
19. Holm, A.; Radon, J.; Künzel, H.M.; Sedlbauer, K. Berechnung des hygrothermischen Verhaltens von Räumen. In WTA-Schriftenreihe; WTA-Publications: München, Germany, 2004; Volume 24, pp. 81-94.

20. Lengsfeld, K.; Holm, A. Entwicklung und Validierung einer hygrothermischen Raumklima-Simulationssoftware WUFI®Plus. In Bauphysik; 29 Heft 3; Ernst \& Sohn Verlag Berlin: Berlin, Germany, 2007; pp. 178-186. 